\title{
LAS GARANTÍAS DEL ACREEDOR FRENTE AL INCUMPLIMIENTO. ESPECIAL REFERENCIA A LA BOLETA BANCARIA DE GARANTÍA
}

\author{
THE CREDITOR'S GUARANTEES FACED TO THE DEBTOR'S BREACH. \\ SPECIAL REFERENCE TO THE COUPON BANK GUARANTEE
}

\section{Cristián Aedo BARrenA*}

RESUMEN: El presente artículo pretende examinar el concepto de garantía, tanto en su sentido amplio, como técnico. Una vez que ha operado el incumplimiento y siempre que sus consecuencias sean imputables al deudor, el acreedor goza de un conjunto de remedios para hacer efectiva la responsabilidad del deudor. Todos estos mecanismos son inherentes a la obligación y se fundamentan en el derecho de prenda general. Además, el acreedor cuenta con la posibilidad de reforzar su posición jurídica, a través de las denominadas cauciones y, en general, las garantías en sentido técnico. A ellas y, especialmente a algunos aspectos de la boleta bancaria de garantía nos referiremos en los párrafos siguientes.

Palabras clave: Derecho de prenda general, garantía, caución, boleta bancaria de garantía.

ABSTRACT: This article aims to explore the concept of guarantee, both in its broad sense, as a technician. Once that has operated the breach and provided that its consequences are attributable to the debtor, the creditor has a set of remedies for the enforcement of liability of the debtor. All these mechanisms are inherent in the obligation and are based on the right overall pledge. In addition, the creditor has the opportunity to strengthen its legal position, through the so-called bonds, and generally guarantees in the technical sense. To them, and especially to some aspects of the coupon bank guarantee discussed in the following paragraphs.

Key words: Right overall pledge, guarantee, coupon bank guarantee.

\section{LAS GARANTÍAS EN SENTIDO AMPLIO: EL MAL DENOMINADO DERECHO DE PRENDA GENERAL}

El concepto de garantía es bastante complejo, pues, como sucede frecuentemente con toda noción jurídica, este no es unívoco. En un sentido amplísimo, comprende todos los mecanismos de tutela del crédito, de ahí que existan dificultades para determinar su contenido ${ }^{1}$. Según Roca: “... la garantía está concebida como un sistema de asegura-

\footnotetext{
* Profesor de Derecho Civil, Escuela de Derecho Universidad Católica del Norte. Doctorando en Derecho por la Universidad de Deusto. Becado por el Ministerio de Educación, proyecto Mecesup UCN0301. Correo electrónico caedo@ucn.cl. Teléfono 55-355725. Dirección postal: Avenida Angamos 0610. Antofagasta.

${ }^{1}$ Como afirma ViCent ChUliá (1996) p. 37: "Esta materia es buen ejemplo que el Derecho es eminentemente lenguaje, con rica y plurivoca terminología, cuyas voces son empleadas con variante significado por cuatro grandes coros hasta hoy faltos de batuta que los coordine: el de los contratantes en la práctica, el de la doctrina, el de la jurisprudencia y el de los legisladores".
} 
miento, legal o voluntario, cuya finalidad esencial es preservar el interés del acreedor, asegurando el cumplimiento de la prestación”. Por eso, en un sentido amplio, el concepto garantía comprende también unos mecanismos cuya finalidad es también el aseguramiento del derecho del crédito, pero que no pueden ser consideradas garantías en sentido técnico ${ }^{2}$.

Siguiendo nuevamente a Roca ${ }^{3}$, en principio deben distinguirse de las garantías, consideradas en sentido técnico, los siguientes mecanismos de tutela: a) las obligaciones derivadas de determinados contratos por causa onerosa, que imponen al deudor una reparación en caso que la cosa no sirva para la finalidad con arreglo a la cual se contrató o bien cuando el acreedor se vea desposeído de la cosa, por existir un mejor derecho anterior; b) las situaciones generales dirigidas a evitar que la conducta del deudor haga ilusoria la prestación pactada. Corresponde a lo que en nuestro sistema conocemos como los derechos auxiliares del acreedor; c) la agregación de una nueva obligación por parte del propio deudor, siendo el ejemplo más claro la cláusula penal ${ }^{4}$; d) tampoco existiría garantía en sentido técnico cuando se transfiere el riesgo a un tercero, como en el caso de los seguros por incumplimiento.

Todos estos mecanismos de tutela, así como las garantías en sentido amplio, se explican desde la perspectiva del mal denominado derecho de prenda general o garantía general de los acreedores. Este derecho es propio del especial vínculo denominado obligación. Para Díez-Picazo, el vínculo jurídico de la obligación es: “...como un pedazo o corte de la vida social que aparece organizado dentro del ordenamiento juridico, por un especial principio jurídico y por una especial función económica o social. De esta naturaleza orgánica derivan todos los derechos, deberes, facultades o cargas de todos los sujetos agrupados en torno a la obligación" 5 .

Esta es la médula de la relación obligatoria y designa la contraposición que existe entre un crédito y una deuda. El crédito es un derecho subjetivo que tiene el acreedor para exigir una conducta. Por su parte, la deuda es un deber jurídico en sentido estricto,

\footnotetext{
2 ROCA TRÍAs (1996) pp. 134 y 135.

${ }^{3}$ ROCA TRÍAS (1996) pp. 135 y 136.

${ }^{4}$ Sin embargo, como indica ROCA TRÍAs (1996) p. 136, la mayoría de la doctrina española considera que la cláusula penal cumple una función de garantía que permite asegurar el cumplimiento de la obligación y el resarcimiento del daño, además de permitir pactar aquellas funciones que las partes crean conveniente, en virtud de la autonomía de la voluntad. Sin embargo, la autora considera la cláusula penal como una pena y no una garantía. Entre otros, DE AMUNÁTEGUI (1993) p. 20, quien señala: "En nuestro Derecho, como veremos, los preceptos dedicados a la cláusula penal parten del respeto a la libertad contractual, admitiéndose incluso una función exclusivamente sancionadora para este tipo de estipulaciones". BLANCO GÓMEZ (1996) pp. 19 y 20. Nuestra doctrina siempre ha reconocido en la cláusula penal el cumplimiento de diversas finalidades. Al respecto, por todos, FUEYO LANERI (1992) pp. 465 y 466, señala: "En atención a las funciones que puede desempeñar este instituto, son tres los ángulos de estudio posibles: A) caución o garantía del cumplimiento de la obligación principal, constituyendo una caución personal, y en tal forma la considera Somarriva en su Tratado de las Cauciones; B) liquidación convencional anticipada. C) multa de arrepentimiento, que, como su nombre lo indica, es una sanción por dejarse de cumplir; pero sin que ella compense necesaria y exactamente la prestación incumplida". SOMARRIVA UNDURRAGA ( $\sin$ año) p. 9, pone el acento en el carácter de garantía personal de la cláusula penal.
}

${ }^{5}$ Díez-PiCAzo (1964) p. 350. 
con determinadas características. Sin embargo, tanto el crédito como la deuda son, ante todo, situaciones jurídicas. Es decir, si miramos la posición del acreedor y la entendemos como situación jurídica, significa que junto con el derecho subjetivo, confluyen también cargas y acaso deberes. Desde el punto de vista del deudor sucede lo mismo, ya que al lado del deber del deudor, existen ciertas facultades y cargas en el desarrollo de la obligación ${ }^{6}$.

La doctrina alemana ha desarrollado la teoría de la deuda y la responsabilidad (Schuld y Haftung), que es la que explica mejor la naturaleza del vínculo obligatorio. De acuerdo con esta teoría pueden distinguirse dos fases en el orden lógico y cronológico: un primer momento, constituido por el débito solamente, es decir, el deber del deudor. Este deber es jurídico, puesto que la ley se ha ocupado de él, señalando la forma de cumplimiento o pago. Por el lado activo de la relación obligatoria, siempre en esta primera etapa lógica y cronológica del deber de cumplimiento, existe, correlativamente, una legítima expectativa del acreedor, también llamada espera o expectativa jurídica, que se cristaliza en el derecho de recibir. Dicha expectativa se encuentra tutelada por el Derecho en caso de incumplimiento por parte del deudor.

En un segundo momento, el deudor queda sometido al poder de agresión del acreedor, constituido por su legítimo derecho a accionar. Esta fase afecta directamente al patrimonio del deudor, cuyos bienes se perseguirán forzadamente para la obtención del cumplimiento. En este estadio, no es posible para el deudor oponerse arbitrariamente a la acción del acreedor. La relación es ahora entre el acreedor y el patrimonio del deudor ${ }^{7}$. Este poder de agresión se funda en lo que en Chile se mal denomina el derecho de prenda general. En virtud de este, los acreedores pueden exigir que se vendan todos los bienes del deudor presentes o futuros, para el cumplimiento de su obligación. Se encuentra consagrado en los artículos 2465 y 2469 del Código Civil chileno.

Como conclusión, la voz garantía puede emplearse en un sentido amplísimo, que le conecta directamente con el denominado derecho de prenda general, que corresponde al régimen de responsabilidad al cual se encuentra sujeto el deudor tanto antes del cumplimiento -para ello baste pensar en algunos derechos auxiliares-, como en la etapa de incumplimiento. De esta garantía sobre el patrimonio del deudor nacen todos los mecanismos de tutela de crédito, los que son inherentes a este. Así, sobre la base de la responsabilidad patrimonial del deudor, el acreedor goza de los derechos de solicitar la resolución del contrato, el cumplimiento forzado, la indemnización de perjuicios y de ejercitar los derechos auxiliares, que constituyen un conjunto de potestades dirigidas unas veces contra el deudor, otras en contra de otros acreedores y, otras, en contra de terceros.

Además de los mecanismos señalados, el acreedor cuenta con acciones específicas derivadas de ciertas relaciones contractuales, como las acciones de "garantía" propia de los contratos a título oneroso. Todos estos mecanismos de tutela, incluida la propia garantía general de los acreedores o derecho de prenda general, no pueden ser calificados

${ }^{6}$ Dí́zZ-Picazo (1964) pp. 349 y ss.

${ }^{7}$ FUEYO (1992) pp. 37 y 38 
de "garantías en sentido propio", pues, siguiendo a Díez-Picazo, son algo inherente al crédito mismo, al que nada añaden ${ }^{8}$.

Pero el mismo derecho de prenda general es el que permite fundar las garantías en sentido técnico, particularmente las cauciones, a las que nos referiremos en el numeral siguiente. Somarriva explica la institución desde la perspectiva de la caución. Se detiene en el análisis del derecho de prenda general -consagrado en nuestro Código Civil, en el artículo 2465-, para luego señalar que las cauciones suplen las deficiencias de la garantía general del acreedor'.

\section{LA GARANTÍA EN SENTIDO TÉCNICO O ESTRICTO. LA CAUCIÓN}

La garantía en sentido técnico, siguiendo a Díez-Picazo, es una norma de derecho o un precepto de autonomía privada que viene a añadir al crédito algo que el crédito no tiene, de tal manera que es esa adición o esta yuxtaposición lo que refuerza al acreedor la seguridad de que su derecho será satisfecho ${ }^{10}$. Para Roca, la garantía en sentido estricto presenta cuatro características: a) permite satisfacer el interés del acreedor de manera independiente, o de manera más específica, que el de los acreedores que no han pactado derechos de garantía concretos; b) actúa sobre bienes concretos del patrimonio del deudor o refuerza las posibilidades del acreedor, añadiendo la responsabilidad de un tercero; c) no afecta a todos los acreedores, sino solo a aquellos que han pactado; d) en algunos supuestos, no se extingue cuando se enajenan los bienes que se han destinado a esta función ${ }^{11}$.

En nuestro sistema varias de las garantías se encuentran reguladas como cauciones, cuya nota distintiva es la accesoriedad. Las cauciones están establecidas en el artículo 46 del Código Civil, el que las define como toda obligación que se contrae para seguridad de una obligación propia o ajena. Los autores distinguen los conceptos de garantía y caución. Las garantías comprenden los diversos medios de que pueda hacer uso el acreedor para ponerse a cubierto de la insolvencia del deudor, mientras que las cauciones, como hemos visto, son aquellas definidas en el artículo 46 del Código Civil. De manera que entre ambas existe un vínculo de género a especie. No todas las garantías son cauciones, pero todas estas son garantías ${ }^{12}$. Como se aprecia, el concepto de garantía que utiliza nuestra doctrina se corresponde con lo que hemos denominado garantía en sentido amplio ${ }^{13}$, mientras que las cauciones constituyen un grupo de garantías en sentido estricto. Algunas de ellas tienen una regulación particular en nuestro sistema y, en otros casos, es la práctica comercial, empresarial o bancaria

\footnotetext{
${ }^{8}$ Díez-Picazo (1983) p. 395. En el mismo sentido, Roca Trías (1996) p. 140

9 SOMARriva (sin año) pp. 7 y 8 . Esta es la misma perspectiva desde la cual analiza la institución DíEZ DUARTE (1991).

10 DíEz-PiCAZO (1983) p. 395.

11 ROCA TRÍAS (1996) p. 143.

12 Así lo expresa Somarriva (sin año) p. 8. En el mismo sentido, LECAROS SÁNCHez (1995) p. 10.

13 Puede apreciase muy claramente esta cuestión en FUEYO (1992) pp. 209 y ss., quien trata como medios compulsivos dirigidos al cumplimiento de las obligaciones las "astreintes", el derecho legal de retención, el apremio personal en las obligaciones de hacer y las arras en garantía
} 
las que las ha ido imponiendo. En el apartado siguiente nos ocuparemos de la boleta bancaria de garantía ${ }^{14}$.

Las cauciones se clasifican en reales y personales. En cuanto a las reales, estas afectan un bien determinado, sea mueble o inmueble y otorgan al acreedor un derecho real sobre la cosa. Son la prenda y la hipoteca. Entre las cauciones personales se ubican la fianza, la cláusula penal y la solidaridad pasiva. Son personales por cuanto se suman patrimonios para responder en caso de insatisfacción del crédito.

Las garantías personales pueden clasificarse en típicas y atípicas y, entre las segundas, algunos autores distinguen entre garantías atípicas, pero análogas a la fianza y garantías totalmente atípicas ${ }^{15}$. A las garantías típicas ya nos hemos referido, siendo las más importantes la solidaridad y la fianza, con todas las modalidades que entre ellas pueden adoptarse. En cuanto a las atípicas, algunos autores españoles incluyen el mandato de crédito, la adhesión de deuda, la asunción de deuda y el contrato autónomo de garantía ${ }^{16}$. Por el mandato de crédito el mandatario se obliga al encargo del mandante de dar crédito a un tercero, respondiendo el mandante de las resultas del negocio ${ }^{17}$. La adhesión a la deuda es una declaración por la que una persona se incorpora como nuevo obligado, añadido junto al primitivo, frente al acreedor, dando lugar a una posición jurídica contractual conjunta ${ }^{18}$. En cuanto a la asunción de deuda, es un contrato por el que una persona se obliga con el deudor a cumplir su obligación sin que este quede liberado de la misma frente al acreedor ${ }^{19}$.

En lo que respecta al contrato autónomo de garantía, este puede situarse en el contexto de los créditos y garantías bancarias. En nuestro sistema, si bien es cierto, no se ha desarrollado el contrato bancario autónomo de garantía, ni la garantía a primer

14 Básicamente, las garantías en sentido técnico que no pueden ser encuadradas en las cauciones son algunas garantías atípicas, como la garantías independientes y, especialmente aquella a primer requerimiento, que, como veremos, alguna doctrina la vincula con la boleta bancaria de garantía. Para otro sector esta no sería más que una caución.

15 ViCEnT CHUlí́ (1996) p. 375

16 Para esta cuestión, véase SÁNCHEZ-CALERo GuILARTe (1995); ViCEnT CHulí́ (1992) pp. 387 y ss.

17 ViCEnT Chulí́ (1992) p. 388, distingue entre mandato inicial de crédito que una vez ejecutado por el mandatario determina la responsabilidad del mandante de forma similar a la de un fiador y el mandato de crédito propio, en el cual el mandante responde como tal, en la medida que debe dejar indemne al mandatario. A nuestro juicio, estas figuras distan bastante de ser contratos atípicos, al menos en nuestro sistema. Tanto los artículos 2116, 2119 y 2120 del Código Civil, como los artículos 233 y 238 del Código de Comercio admiten esta clase de mandatos, los que se explican mejor si se recurre a la clásica distinción entre mandato a nombre propio o a nombre ajeno. En el caso de la comisión, el Código de Comercio admite que aun actuando el comisionista a nombre propio, puede el comitente tomar sobre sí el negocio, en cuyo caso, conforme al artículo 258, se constituye en fiador de las obligaciones pactadas con el comisionista. Es un efecto similar al contemplado en el artículo 1635 del Código Civil para la novación imperfecta.

18 Como hemos visto, esta no es más que la descripción de la novación imperfecta por ex promisión imperfecta, es decir, cuando un nuevo deudor toma la iniciativa. Es dudoso que en nuestro sistema esta figura pueda ser calificada de "atípica" desde que se encuentra contemplada en el artículo 1635 del Código Civil y en menor medida en el artículo 258 del Código de Comercio.

19 Nuevamente se trata de un supuesto que no puede ser calificado de "atípico", pues corresponde más o menos a lo que en nuestro sistema se conoce como delegación imperfecta, regulado junto con la novación y cuyos efectos se consagran en el citado artículo 1635 del Código Civil. 
requerimiento, desde hace bastante tiempo opera en la práctica comercial y bancaria la denominada boleta bancaria de garantía, a la que nos referiremos en el apartado siguiente. Según Caprile, el vínculo entre ambas figuras, especialmente con la carta de crédito fronterizo stand by, consiste en las razones que originaron ambas figuras, pero además indica que se da una identidad en cuanto a la finalidad que persiguen y a su naturaleza jurídica, de manera que para el autor, la boleta bancaria no es más que una garantía a primer requerimiento que opera en el derecho interno chileno ${ }^{20}$. A la boleta bancaria de garantía nos referiremos en los párrafos siguientes.

\section{LA BOLETA BANCARIA DE GARANTÍA: CONCEPTO Y NATURALEZA JURÍDICA}

La boleta bancaria de garantía supone que un sujeto, denominado tomador, solicita a una institución bancaria, la emisión de un documento denominado depósito o boleta de garantía, para asegurar a un tercero, denominado beneficiario, el cumplimiento de una obligación derivada de un contrato. La figura admite dos modalidades, según si el tomador tiene la disponibilidad de fondos equivalentes al importe de la boleta y está dispuesto a inmovilizarlos en poder del banco. Cuando el depósito se constituye en forma efectiva por el tomador, se le llama propiamente depósito en garantía; cuando el tomador obtiene un crédito en el mismo banco emisor, que se documenta generalmente mediante un pagaré, se le denomina "boleta de garantía"21. Winter la define como: "Un documento emitido por un banco (banco emisor) a solicitud y por cuenta de un cliente (tomador), en virtud del cual el banco se obliga a pagar a la persona cuyo favor se extiende (beneficiario) una cierta cantidad de dinero, contra la sola presentación del documento de cobro"22, 23.

20 CAPrile BiermanN (2002) pp. 18 y 19.

21 Así lo señala CAprile Biermann (2002) p. 35. En cuanto a las modalidades de la operación, puede consultarse también la clásica obra de GONZÁLEZ SAAVEDRA (1962) pp. 11 y ss. Es la propia Ley General de Bancos, en el artículo $69 \mathrm{~N}^{\circ}$ 13, la que distingue entre depósito y boleta de garantía. Con todo, siguiendo nuevamente a CAPRILE BIERMANN (2002) pp. 35 y 36, estos distintos mecanismos no alteran la naturaleza jurídica del instrumento, ni afectan la posición jurídica del beneficiario.

22 Winter IgUalt (1995) p. 15

${ }^{23}$ Los autores están de acuerdo en que se trata de una figura propia de la práctica comercial bancaria chilena. Ya en 1962, en su memoria de prueba GONZÁLEZ SAAVEDRA (1962) pp. 9 y ss. señalaba que era original del ordenamiento jurídico chileno. En el mismo sentido y al describir sus características, WINTER IGUALT (1995) p. 17, aunque reconociéndole, al igual que CAPRILE BIERMANN (2002) pp. 18 y 19, ciertos vínculos con la carta de crédito stand by. Su origen se encuentra en la práctica bancaria y posteriormente fue incorporada por el legislador al ordenamiento jurídico, como explica GONZÁlEZ SAAVEDRA (1962) p. 9, mediante Decreto con Fuerza de Ley $\mathrm{N}^{\circ}$ 192, de 15 de mayo de 1931, que modificó la ley bancaria de esa época -Decreto Ley $\mathrm{N}^{\circ} 559$, de 1925-. Actualmente está regulada en el artículo $69 \mathrm{~N}^{\circ} 13$ de la Ley General de Bancos, DFL $\mathrm{N}^{\circ}$ 3, de 19 de diciembre de 1997, que fijó el texto refundido, sistematizado y concordado de la Ley General de Bancos. CAPrile Biermann (2002) pp. 26 y ss., cita las otras fuentes normativas de la boleta bancaria, además de los textos legales que la exigen. El autor, desde luego, no podía incluir la importante modificación contenida por la incorporación del artículo 138 bis en el DFL 458, Ley General de Urbanismo y Construcciones, de 13 de abril de 1976. La reforma fue operada por la Ley 19. 382, de 3 de febrero de 2004 y con una modificación posterior, por Ley 20.007, de 11 de abril de 2005. Con el nuevo artículo 138 bis se va a regular y exigir la boleta bancaria de garantía para los contratos promesa celebrados entre privados. 
Tal vez el aspecto más importante de la boleta bancaria de garantía dice relación con la determinación de su naturaleza jurídica. Como indica Caprile, a falta de norma especial que la regule, deben aplicarse las normas generales, pero ellas dependerán de la calificación y naturaleza que se atribuya al instituto ${ }^{24}$. Al respecto se han formulado varias teorías. Analizaremos solo las más importantes, de las que destacaremos sus principales virtudes y debilidades.

Según una tesis, se trataría de un acto complejo, consistente en un depósito irregular unido a una estipulación en favor del beneficiario, que da lugar a una prenda de dinero. En consecuencia, no se trataría de una figura distinta de otras, con naturaleza y efectos propios. Por el contrario, el tomador efectuaría un depósito de dinero en las arcas del banco emisor, el que tendría un carácter irregular, conforme a lo dispuesto en el artículo 2221 del Código Civil. Luego, el depositante estipularía en favor de un tercero, el beneficiario, quien no participa en la convención. El documento constituiría, finalmente, una prenda de dinero ${ }^{25}$. En suma, entre tomador y banco existiría un contrato de depósito; entre el banco y el beneficiario las relaciones se regirían por una estipulación en favor de un tercero; y, las del tomador con el beneficiario por las de la prenda de dinero ${ }^{26}$.

Se ha dicho que esta postura presenta algunas deficiencias notorias. La más importante dice relación con el carácter accesorio que posee el contrato de prenda. Todas las cauciones presentan como característica la accesoriedad, es decir, sin ser contratos dependientes, se encuentran vinculados al acto o contrato al que acceden y penden de las obligaciones que garantizan. De esta manera, la extinción del contrato principal trae como consecuencia la extinción de la caución ${ }^{27}$. Es evidente que ello no ocurre con la boleta bancaria. Prueba de ello es que la boleta debe ser pagada al beneficiario sin que el banco pueda cuestionar la oportunidad del pago, ni excepcionarse en el contrato base suscrito por el tomador y el beneficiario. Por su parte, el tomador no puede impedir, como regla general, que el banco pague la boleta al beneficiario. A partir del año 1996, nuestra jurisprudencia se ha uniformado en rechazar recursos de protección planteados por el tomador destinados a impedir el pago de la boleta ${ }^{28}$.

${ }^{24}$ CAPRile Biermann (2002) p. 32.

${ }^{25}$ En la sentencia de la Corte de Apelaciones de Concepción, de 19 de julio de 2000 (indicador LexisNexis 22146), cuyas partes eran Servicio de Vivienda y Urbanización Bío Bío Empresa de Servicios Sanitarios Bío Bío S. A., se califica la boleta bancaria de garantía como una prenda del tomador a favor del beneficiario. La Corte estimó que: "El beneficiario en cuyo favor se emitió la letra se hace dueño de ese depósito y el tomador no puede oponerse a que el banco pague su monto al beneficiario ni aunque alegue que este no ha cumplido la obligación caucionada, porque ello desvirtúa la prenda, y el banco está también obligado por su parte a pagar sin delación".

${ }^{26}$ Es la teoría de Varela Varela (1948). Le sigue GonZÁlez SaAVEdra (1962) pp. 45 y ss. Es la misma opinión que señala Somarriva (sin año) p. 231. Según CAPRile Biermann (2002) p. 50, es la teoría mayoritaria en nuestra doctrina.

27 Así lo dispone el artículo $2381 \mathrm{~N}^{\circ} 3$ para la fianza, artículo 2406 para la prenda y el artículo 2434 para la hipoteca.

${ }^{28}$ Es bastante conocido el fallo de la Corte de Apelaciones de Santiago, de 27 de septiembre de 1996, publicado en RDJ, t. $94 . \mathrm{N}^{\circ} 2$, sección quinta, pp. 147 y ss, por el que se resolvió el recurso de protección interpuesto por Dinamex Chile S. A. en contra del Cuerpo Militar del Trabajo. En el caso sublite, el 
De otra parte, Puelma Accorsi, critica la tesis descrita señalando que no existiría una genuina entrega del tomador al beneficiario. En este sentido, Caprile ${ }^{29}$ explica que en las obligaciones de dar es fundamental el ánimo con el que se entregue el dinero. Sin ir más lejos, el Código Civil admite que pueda celebrarse el contrato de compraventa con arras como prenda de la celebración del contrato, quedando estas como parte del precio o en señal de quedar convenidos, conforme a los artículos 1803 a 1805.

Lecaros explica que el caso de la prenda de dinero, el acreedor se haría dueño del dinero, por lo que el contrato se desfiguraría y pasaría a ser título traslaticio de dominio. Agrega: "El acreedor se haría dueño del dinero, pudiendo usarlo, gozarlo y disponer de él, obligándose a restituir una suma de dinero equivalente una vez satisfecha la deuda principal o garantizada. Guarda, en tal sentido mucha relación con el cuasi usufructo, con el mutuo y sobre todo con el depósito irregular (artículo 2395 y 2221). La ventaja que tiene la prenda de dinero es que evita la necesidad de realizarla cuando el deudor no cumple la obligación garantizada. Se aproximaría, en tal caso a una compraventa de cosas muebles con pacto de retroventa. Todo lo dicho respecto de la prenda de dinero es aplicable a los vales vista bancarios o boletas de garantía"30. Es por ello que este sector doctrinal justifica la imposibilidad de oponerse al pago de la letra, en virtud del dominio que detenta el acreedor respecto del dinero dado en prenda. El fallo de la Corte de Concepción, de 19 de julio de 2000, que hemos citado, emplea igual justificación, cuando resuelve que el tomador

recurrente se había adjudicado el suministro de diversos vehículos militares, entregando dos boletas bancarias de garantía; una, del 2\%, del precio del contrato, para garantizar la seriedad de la oferta; y, otra, del $5 \%$ de la oferta, para garantizar el fiel cumplimiento del contrato. Considerando el Ejército que existía incumplimiento por parte de Dinamex Chile S. A., hizo efectivo el cobro de la boleta bancaria, pretendiendo aplicarla a una cláusula penal compensatoria que las partes habían pactado. La Corte estimó que dicho procedimiento constituía un atentado a varias garantías constitucionales, especialmente la igualdad ante la ley y el debido proceso. La Corte estimó que las partes estaban sometidas al principio de igualdad, conforme al artículo 1545 del Código Civil y que la autoridad administrativa no podía decidir por sí y ante sí la existencia de un incumplimiento, ya que, de lo contrario, se vulneraría la garantía del debido proceso. Esta misma circunstancia constituiría una violación del derecho a un juez natural, reconocido en el artículo $19 \mathrm{~N}^{\circ} 3$ del texto constitucional.

Sin embargo, con posterioridad al fallo en comento, nuestros tribunales se uniformaron en el rechazo de los recursos de protección que pretendían detener el pago de las boletas bancarias de garantía, aun cuando ninguno de ellos se hace cargo del problema de su naturaleza jurídica. Podemos citar algunos ejemplos que determinan esta tendencia. Así, en el fallo de la Corte Suprema de 25 de mayo de 2005 (indicador LexisNexis 32239), sobre un recurso de protección interpuesto por Juan Opazo Ramírez contra la Municipalidad de Antofagasta, se intentó paralizar el cobro de una boleta bancaria de garantía. En primera instancia, la Corte de Apelaciones de Antofagasta, por sentencia de 13 de abril de 2005, estimó que la Municipalidad se encontraba facultada para poner término unilateral al contrato suscrito con el recurrente consistente en la construcción de un parque deportivo y de esparcimiento y hacer efectivo el cobro de la boleta bancaria de garantía, si existían atrasos injustificados de las obras. El criterio fue confirmado plenamente por la Corte Suprema en el fallo antes citado.

En el fallo de la Corte de Apelaciones de Rancagua, de 9 de febrero de 2007, no recurrido (indicador 35910 LexisNexis), en un recurso de protección deducido por Manuel Muñoz Guzmán en contra del Gobierno Regional de la VI Región, la Corte estimó que el cobro de boletas bancarias de garantía destinadas a caucionar el fiel cumplimiento de un contrato no vulneraba el derecho de propiedad del tomador de la boleta, toda vez que las partes lo habían pactado expresamente.

${ }^{29}$ CAPrile Biermann (2002) pp. 52 y ss. En el mismo sentido, Somarriva (sin año) pp. 230 y 231.

30 LECAROS SÁNCHEZ (1995) p. 29. 
no puede oponerse al pago de la boleta, pues el beneficiario en cuyo favor se otorgó la boleta se hace dueño del depósito en su favor.

Por otra parte, debemos reconocer que esta doctrina lleva cierta razón cuando afirma que la relación beneficiario-tomador está constituida por una prenda, solo en cuanto el artículo $69 \mathrm{~N}^{\circ} 13$ de la Ley General de Bancos dispone que las boletas bancarias de garantía no son embargables por terceros, de donde se deduce que las partes pueden hacerlo. En este caso, al igual que en el artículo $1464 \mathrm{~N}^{\circ} 3$ del Código Civil, el embargo es entendido en un sentido amplio, comprendiendo todas las medidas judiciales que embaracen o limiten la libre disposición del bien. Luego, si las partes pueden embargar o deducir medidas precautorias en contra de la boleta, cabe preguntarse: ¡en virtud de cuál razón jurídica podría el tomador embargar y solicitar una medida precautoria en relación con la boleta bancaria? A nuestro juicio, la única razón jurídica por la que el tomador puede solicitar una medida de este tipo consiste en una discusión sobre el contrato que da origen a la boleta bancaria. Es decir, el tomador podrá sostener en juicio cuestiones relativas al contrato de origen y en virtud de ello puede pedir una medida precautoria, prejudicial o no, en relación con la boleta. Ello nos hace pensar que la boleta no tiene un carácter autónomo como se pretende; sino, por el contrario, genuinamente accesorio. De hecho, el Capítulo 8-11 de la Recopilación de Normas de la Superintendencia de Bancos e Instituciones Financieras califica la boleta como "caución". Cuando así lo hace, nos parece que parte del supuesto que se trata de una caución, definida en los términos del artículo 46 del Código Civil, en relación con el artículo 1442 del Código Civil, disposiciones que definen la caución y regulan los contratos accesorios ${ }^{31}$.

Para Puelma, las relaciones entre tomador y el banco y entre este y el beneficiario serían idénticas a las de la doctrina anterior. Es decir, se trataría de un depósito irregular unido a una estipulación en favor de otro. Pero, a diferencia de la teoría anterior, no ve en las relaciones entre tomador y beneficiario una prenda de dinero, por no existir entrega de cosa alguna, dado que la prenda es un contrato real, ni las partes han celebrado dicho contrato. Por el contrario estima que se trata de un negocio fiduciario. El tomador, al hacer un depósito a favor de un tercero está realizando un acto fiduciario que es real. Se trataría de un negocio fiduciario con fines de garantía, incorporado en el concepto amplio de caución ${ }^{32}$. En general, pueden serle formuladas las mismas críticas que a la doctrina anterior.

Para Varela Morgan la boleta de garantía sería un título de crédito que contiene una promesa unilateral del banco, incondicionada y abstracta, de la que emana la obligación de este a favor del beneficiario. Agrega que no se trata de un depósito para el banco, ni de un préstamo para el tomador, porque el banco no necesita dinero para otorgarla; por el contrario, se trataría de un servicio que presta a su cliente. Sostiene que el depósito y el mutuo, en su caso, se encontrarían unidos de manera indisoluble. Así

31 Para un tratamiento de los contratos principales y accesorios véase LÓPEZ SANTA MARÍA (2005) pp. 128 y 129, quien señala expresamente que los contratos accesorios son las cauciones.

32 Puelma ACCORSI (1971) pp. 88 y 89. 
como se puede dar en garantía una letra, mediante endoso, se podría dar en garantía la obligación del banco frente al beneficiario de la boleta, constituyendo la caución un contrato de prenda, debido a que se entrega al acreedor una cosa mueble -la obligación del banco- para seguridad de su crédito ${ }^{33}$.

También para Winter, la boleta bancaria de garantía sería un título de crédito intransferible, emitido por un banco a nombre propio, pero en virtud de un mandato del tomador, con el exclusivo objeto de que este último lo utilice para garantizar al beneficiario el cumplimiento de la obligación que se consigna en su texto, y que es pagadero con la sola presentación al cobro. Agrega que se trataría de un negocio compuesto, que incorpora distintos actos jurídicos: un mandato mercantil entre el tomador y el banco, un título de crédito para explicar las relaciones entre el banco y el beneficiario; y un contrato innominado de garantía para explicar las relaciones entre el tomador y el beneficiario ${ }^{34}$.

Esta teoría presenta el problema que el instrumento no se aviene con la esencia de los títulos valores. Estos consisten en un documento que incorpora un derecho, de manera que dicho derecho circula con el documento, emanando los caracteres de independencia y abstracción propios de los efectos de comercio ${ }^{35}$. En cambio, la boleta bancaria de garantía tiene como esencia o nace esencialmente para garantizar una obligación. Además, desde su nacimiento, no está destinada a circular. La Recopilación de Normas de la Superintendencia de Bancos e Instituciones Financieras, Capítulo 8-11, en el número 1, dispone que la boleta bancaria es una caución que tiene por objeto garantizar el fiel cumplimiento de una obligación. Y en el apartado 1.1 se agrega: "Dado que la boleta es una caución, en ningún caso puede disponerse de ella para una finalidad distinta de aquella para la cual fue tomada. Por consiguiente se trata de un documento nominativo que no admite endoso por parte del beneficiario, sino solamente su cancelación en caso de hacerse efectiva, cobrando su importe o bien, para hacer su devolución al respectivo tomador de la misma, para que este a su vez la devuelva al banco, a fin de dar por cancelada la garantía". Cierto es que el artículo 30 de la Ley $N^{\circ} 18.092$ admite que la letra puede ser endosada en garantía, constituyendo una prenda, pero los títulos valores y, especialmente los efectos de comercio, no pueden ser girados en garantía, porque se desnaturalizan.

Sin embargo, hay algunos argumentos, de forma y de fondo que permiten argumentar en favor de esta teoría. En lo que respecta a las de forma, si uno lee atentamente las disposiciones de la Superintendencia de Bancos e Instituciones Financieras, Capítulo 8-11, tal parece que estas asumen que se trata de un título valor, al que incluso le resultan aplicables las disposiciones de la Ley $\mathrm{N}^{\circ}$ 18. 092. En el apartado 1. 2, letra b), se dispone que: "Acorde con la función para las que fueron creadas, en la extensión de una boleta de garantía debe dársela a esta el carácter de nominativa y no endosable. Para este efecto deberá utilizarse únicamente la forma "El Banco... pagará a (nombre del beneficiario)", atendido que, sobre la base de lo preceptuado por el artículo $1^{\circ}$ de la Ley $N^{\circ} 18.552$,

\footnotetext{
33 Morgan Varela, Raúl, citado por GonZÁlez SaAVEdra (1962) pp. 27 y ss.

34 WinTER (1995) (n 22), pp. 88 y ss.

35 Para esta cuestión, véase PUELMA ACCORSI (2006) pp. 19 y ss.
} 
de 20 de septiembre de 1986 relativo al tratamiento de los títulos de crédito, se podría considerar que el documento no es nominativo si se utilizan cláusulas tales como "a favor" o "a la orden". Por otra parte, como la Ley $N^{\circ} 18.092$ sobre letras de cambio y pagarés, en su artículo 18, permite el endoso aun cuando el documento no esté a la orden, conviene agregar en las boletas de garantía el término "no endosable", que el mismo artículo establece para que no proceda el endoso traslaticio de dominio, permitiendo sin embargo el endoso en comisión de cobranza, todo lo cual se aviene con la naturaleza jurídica de este especial documento".

Es claro que las expresiones que utiliza la regulación de la Superintendencia consideran en algunas normas que la boleta es un título valor y, más concretamente, un efecto de comercio, pues de otro modo no tendría sentido que discurriera sobre la aplicación de la Ley $\mathrm{N}^{\circ} 18.552$ y la Ley $\mathrm{N}^{\circ}$ 18. 092. Primero dispone que las boletas deben ser nominativas, para evitar la aplicación de la Ley 18. 552. Luego, agrega que es conveniente agregar la expresión "no endosable", considerando implícitamente que el estatuto supletorio de la boleta sería la Ley $\mathrm{N}^{\circ} 18.092^{36}$.

En cuanto al fondo, creemos que el principio de inoponibilidad de excepciones que evidentemente opera en la boleta, respecto de las relaciones banco-beneficiario, pueden ser explicadas desde la teoría de los títulos valores sin necesidad de recurrir a la teoría del contrato autónomo de garantía. Sobre esta cuestión volveremos luego, al examinar la teoría que sustenta Caprile.

Por último, para Caprile, la boleta bancaria tiene el carácter de garantía a primer requerimiento, constituyendo un contrato atípico, pero nominado. Para el autor, todas las teorías anteriores disgregan los vínculos que existen entre tomador, banco y beneficiario, para deducir desde ahí distintas relaciones contractuales típicas. En cambio, la doctrina de la garantía autónoma permite, una explicación unitaria para todas las relaciones envueltas en la generación de la boleta ${ }^{37}$.

El contrato abstracto o autónomo de garantía y su subespecie, el contrato a primer requerimiento o primera demanda, de raíz germana, es un contrato estrictamente bancario ${ }^{38}$. Como indica Sánchez-Calero Guilarte, siguiendo a Canaris, el

\footnotetext{
${ }^{36} \mathrm{Si}$ se considera que la boleta, en cuanto documento que incorpora un derecho autónomo y que circula con el documento, es un título valor, en virtud del artículo $1^{\circ}$ de la Ley 18. 552, de 20 de septiembre de 1986, le sería aplicable el endoso regulado en la Ley 18. 092. En este sentido, la última normativa indicada dispone que la letra puede ser endosada en garantía, lo que constituye una prenda. En todo caso, cabe tener presente que se trata de una opinión discutible, desde que, conforme al Capítulo 8-11 de la Recopilación de Normas de la Superintendencia de Bancos e Instituciones Financieras, la boleta es nominativa e intransferible y la ley que hemos citado exige que los títulos sean a la orden. Lo curioso es que normalmente las letras de cambio se emiten nominativas y, no obstante, pueden endosarse, salvo que incorporen la cláusula no endosable.

37 CAPRILE BIERMANN (2002) pp. 113 y 114. En España, los autores que se refieren a la garantía a primer requerimiento distinguen las distintas relaciones que emanan del contrato. Así, SÁNCHEZ CALERO GUILARTE (1995) p. 136, sostiene que las distintas relaciones jurídicas dan lugar a contratos distintos. Así, entre el tomador o requeriente y el banco existiría un mandato mercantil, como en la mayoría de los contratos bancarios. Entre el banco y el beneficiario de la garantía surge el contrato de garantía en sentido estricto. Finalmente, entre el requirente o tomador y el beneficiario, pueden encontrarse unidos por contratos de diversas naturalezas. En el mismo sentido, SAN JUAN CRUCELAEGUI (2004) pp. 235 y ss. ${ }^{38}$ Para un análisis general de los contratos bancarios en Chile, véase SANDOVAL LÓPEZ (2003) pp. 301 y ss.
} 
contrato autónomo de garantía: "es aquel por el que el banco garante responde frente al beneficiario por la obtención de un determinado o el mantenimiento de una concreta situación, de modo que si uno u otro no llegaran a producirse el garante se vería obligado a reemplazar el interés defraudado en tal supuesto al beneficiario" 39 . Por su parte, Carrasco Perera señala que es: "el contrato por la que un tercero (normalmente entidad de crédito) intercede ante el acreedor garantizando el cumplimiento de determinadas obligaciones de un deudor principal, con la particularidad de que la obligación de pago del garante se funda en, y vence por la sola reclamación de pago hecha por el acreedor -unida acaso a otros requisitos formales-, sin que el garante pueda discutir la corrección material de esta reclamación desde la perspectiva del deudor principal ni oponer al pago las excepciones que este deudor pudiera oponer al acreedor en relación de valuta" 40 .

Según Caprile, la boleta bancaria responde a las características esenciales de la garantía autónoma a primer requerimiento. Se trataría de una garantía personal, por oposición a las reales, destacando dicho carácter, debido a que la tesis mayoritaria la considera una prenda y, por tanto, una garantía real. Además, explica que a su respecto opera el principio de inoponibilidad de las excepciones, en el sentido que el garante no puede excusarse de pagar invocando excepciones o defensas derivadas del contrato garantizado. También explica que la boleta bancaria es una garantía autónoma, siendo este el rasgo fundamental de las garantías a primer requerimiento, constituyendo su impronta precisamente la inoponibilidad de las excepciones. En ello se distinguiría de la fianza, la que, en cuanto caución, tiene un carácter accesorio ${ }^{41}$.

En efecto, los autores suelen distinguir el contrato autónomo de garantía de la fianza, especialmente porque este último carece de la nota de accesoriedad propia del primero. De acuerdo con lo dispuesto en el artículo 1442 del Código Civil, el contrato es principal cuando subsiste por sí mismo y accesorio, cuando tiene por objeto asegurar el cumplimiento de una obligación principal, de manera que no puede subsistir sin ella. Por el contrario, como indica Sánchez-Calero Guilarte, en el contrato de garantía no se busca reforzar el crédito del acreedor de esta, sino que prima asegurar la satisfacción de un interés económico. El banco no cumple en lugar del deudor, sino que asume una obligación distinta, consistente siempre en el pago de una cantidad de dinero. Para su cumplimiento bastará la reclamación del acreedor formulada de acuerdo a las condiciones establecidas en el contrato de garantía, bien por la simple manifestación de voluntad del beneficiario o estableciendo que dicha reclamación deba ir acompañada de documentos. Agrega el autor: "De este modo, la falta de la accesoriedad se convierte en la fundamental nota diferenciadora de los avales bancarios frente a la fianza. Parece oportuno advertir, aunque ello pueda parecer incluso obvio, que al referirnos al contrato de garantía bancaria estamos pensando exclusivamente en aquellas modalidades del mismo que realmente

\footnotetext{
39 SANCHEZ-CALERO GuilarTe (1995) pp. 139 a 141. En este sentido el autor señala que la prestación del banco es el núcleo del contenido de este contrato de garantía.

40 Carrasco Perera (1996) pp. 687, 688 y 689.

41 CAPrile BiermanN (2002) pp. 126 a 129
} 
constituyen un contrato de garantía personal distinto de la fianza, y más concretamente, a las garantías a primera demanda" 42 .

Como hemos visto, Caprile señala que la boleta bancaria de garantía constituiría una garantía a primer requerimiento, en base a tres características: se trataría de una garantía personal y no real; y es autónomo, especialmente al operar el principio de inoponibilidad de las excepciones.

La verdad es que la tesis de Caprile, con todo lo interesante que es, no permite resolver el problema que el mismo autor se plantea primeramente, por cuanto afirmar que se trata de un contrato atípico o autónomo de garantía no determina la norma de fondo aplicable; más bien, se genera precisamente ese problema. La doctrina más moderna viene distinguiendo entre contratos nominados-innominados y contratos típicosatípicos. Los primeros tienen un nombre y fisonomía propia, pero no se encuentran regulados en la ley. Los segundos no encuentran regulación legal o la que existe es escasa o insuficiente, de manera que debe ser asimilado a alguna figura típica, a los efectos de precisar la normativa de fondo aplicable. Así, pueden existir contratos típicos y nominados o típicos e innominados, así como contratos atípicos innominados. En el caso de la boleta bancaria de garantía, consideramos que se trata de un contrato típico y nominado. Pero la consagración legislativa solo alcanza a su mención y la normativa de la Superintendencia de Bancos e Instituciones Financieras no permite resolver el problema de la naturaleza jurídica, que indique la normativa supletoria aplicable.

Precisamente por ello surge la necesidad de determinar las normas de fondo aplicables. Afirmar que se trata de una figura nueva, distinta de las típicas, solo permite volver al punto de partida. Es por eso que Carrasco Perera plantea una posición más crítica del instituto, que desde luego compartimos. Al respecto, el autor citado califica el contrato simplemente como una fianza, que admite distintas configuraciones, considerando inútil elaborar una construcción dogmática de un contrato que incluya la cláusula a primer requerimiento. Más adelante explica que la opinión común indica se trata de un tipo contractual distinto de la fianza, caracterizado por el carácter autónomo y no accesorio de la obligación del garante, que comporta independencia respecto de la obligación garantizada. Agrega el autor: "Esta desconexión entre la garantía y su causa material se expresa comúnmente mediante la afirmación de que la gpr no "garantiza" el cumplimiento de la obligación básica, sino la "indemnidad" del beneficiario para cuando ocurra un suceso, especificado en la garantía, y que es la falta de cumplimiento del deudor ordenante de la garantía". Por eso, para este autor la garantía a primer requerimiento no presenta las notas de abstracción e independencia que parte de la doctrina señala, pues en su concepto si bien es cierto este contrato crea una obligación distinta y autónoma de la obliga-

\footnotetext{
42 SánChez-Calero Guilarte (1995) pp. 102 y 103. En el mismo sentido y diferenciando claramente el instituto de la fianza, SAN JUAN CRUCELAEgUi (2004) pp. 223 y 224, quien explica que en la práctica y derecho americano se distinguen claramente ambas figuras, empleando la expresión guaranty, que se corresponde con el tipo de garantía accesoria y stand-by, que se corresponde con el tipo de garantía accesoria. CARRASCO PERERA (1996) pp. 688 y 689, en cambio, plantea una postura más crítica del contrato, pues lo considera simplemente como un contrato de fianza, que admite distintas configuraciones, considerando inútil elaborar una construcción dogmática de un contrato que incluya la cláusula a primer requerimiento.
} 
ción principal, lo mismo ocurre en la fianza. Así, es un abuso de la semántica distinguir entre "cumplir por otro", para la fianza e "indemnizar un resultado ajeno", en el caso del contrato a primer requerimiento, en circunstancias que en ambos casos se asegura un resultado que consiste en el incumplimiento de una obligación principal, pero la obligación del garante emana de su propio contrato. Finalmente, sostiene que la garantía a primer requerimiento no es una obligación abstracta, pues tiene un fin típico, que no es otro que la finalidad de garantía respecto de otra obligación ${ }^{43}$.

De otra parte, el principio de inoponibilidad de las excepciones es una característica que se presenta también en los títulos de crédito y, especialmente, en los efectos de comercio. El principio, consagrado en el artículo 28 de la Ley 18. 092 significa que el obligado al pago, cualquiera que este sea (librador, aceptante, endosante o avalista), no puede oponer excepciones que estén fundadas en relaciones personales con anteriores portadores de la letra, a diferencia de lo que ocurre con la cesión de créditos ${ }^{44,45}$.

43 Carrasco Perera (1996) pp. 695, 726, 727 y 728. Le sigue SÁnChez Lerma (2001) pp. 283 y 284, quien considera la existencia de cierta equivalencia entre la cláusula a primer requerimiento y el pacto de solidaridad de la fianza, pues en tal caso, según la autora, el fiador, además de perder el beneficio de excusión responde frente al acreedor sin necesidad de incumplimiento por parte del deudor principal; en tal caso el acreedor puede dirigirse en contra del fiador o el deudor principal solo al vencimiento de la obligación, pero subsistiendo la posibilidad de que el fiador oponga las excepciones derivadas del vínculo principal. En cambio, sostiene, hay subsidiariedad en la fianza cuando el acreedor deba acreditar el incumplimiento para dirigirse en contra del garante. En contra de esta posición, como hemos visto y distinguiendo claramente el contrato independiente de garantía de la fianza, SAN JuAn CruCELAEGUi (2004) pp. 225, 226, 227 y 229, quien ni siquiera cree posible la aplicación supletoria de la regulación legal de la fianza. En este sentido indica que no es posible pactar solidaridad en la garantía a primer requerimiento: "La solidaridad es una característica típica y posible de la fianza cuando asi es pactada por las partes, en clara conexión y conformidad con el carácter de accesoriedad de aquéllas, por lo que parece, ya desde un principio, caracteristica inadecuada para un tipo contractual como es el de las garantias independientes, que se destaca por su carácter principal (...) La solidaridad es noción extraña a las garantías independientes, en las que cada uno de los obligados responde de su propia obligación, por lo que el garante no asume solidariamente la obligación del garantizado, sino exclusivamente la obligación de garantía".

${ }^{44}$ En verdad, el denominado principio de inoponibilidad de excepciones deriva del carácter autónomo o independiente de los títulos valores. Dicha autonomía se refleja en un triple aspecto: a) la independencia que cada uno de los poseedores del título tiene respecto de los poseedores anteriores del mismo. Esto significa que, a diferencia del derecho común, el que adquiere el título adquiere un derecho distinto e independiente de las relaciones producidas entre los anteriores titulares del documento. Este es el aspecto consagrado en el artículo 28 de la Ley 18.092 y que se conoce como principio de independencia de firmas; b) en un segundo aspecto, la autonomía implica que cada uno de los actos ejecutados sobre el título valor son independientes entre sí. Así, por ejemplo, con arreglo al artículo 7 de la Ley 18.092, la incapacidad de algunos de los signatarios de una letra de cambio, el hecho que parezcan firmas falsas o falsificadas, no invalida las obligaciones de los demás firmantes del título; c) en un último aspecto, la independencia se relaciona con el carácter abstracto que algunos títulos valores tienen, en especial los efectos de comercio. Esta característica está consagrada en el artículo 12 de la Ley 18.092, que regula el denominado efecto no extintivo. Dispone la norma que las operaciones sobre letra de cambio no extingue las relaciones que les dan origen, es decir, no producen novación, salvo pacto expreso, pero si el obligado paga la letra, se extingue también la obligación originaria hasta el monto de lo pagado.

45 Varios autores reconocen las similitudes del principio de inoponibilidad de excepciones que opera en los actos cambiarios y en la garantía a primer requerimiento. Así, SÁNCHEZ LERMA (2001) p. 283, señala que al igual que en las obligaciones cambiarias, en las garantías a primer requerimiento, la abstracción da lugar al efecto de la inoponibilidad de las excepciones que es en las garantías a primera demanda, un efecto de su 
Pero fuera de esta cuestión, lo cierto es que la teoría de Caprile tampoco recibe apoyo normativo. Aun cuando la pura descripción de la boleta coincide con la definición del contrato a primer requerimiento, por una parte, el artículo $69 \mathrm{~N}^{\circ} 13$ de la Ley General de Bancos dispone que esta no es embargable por terceros. Si las partes pueden embargar la boleta, especialmente el tomador o deudor, es porque esta no se encuentra desvinculada del contrato principal o base de la cual emana. Ello nos hace suponer que la ley la considera, lisa y llanamente, una prenda. Por su parte, la normativa de la Superintendencia de Bancos e Instituciones Financieras tampoco contribuye a la teoría, pues en varios pasajes se la califica de una caución y, por tanto, de un contrato accesorio. Así, en el número 1.1 se dispone que: "Ya sea que el depósito se constituya en efectivo o como consecuencia de un préstamo bancario y cualquiera sea la obligación que caucione". Más adelante se señala: "Dado que la boleta es una caución, en ningún caso puede disponerse de ella para una finalidad distinta de aquella para la cual fue tomada" 46.

Esta cuestión, sin embargo, requiere una explicación un poco más detallada. Por un lado, es claro que en la boleta bancaria el garante -el banco- no puede oponer excepciones al pago que se funden en el vínculo que existe entre el deudor o tomador y el beneficiario-acreedor. Como hemos visto, la teoría de la prenda de dinero justifica esta cuestión sosteniendo que al tratarse de una prenda de dinero y, por tanto, una prenda irregular, el beneficiario se haría dueño del dinero depositado en su favor. En cambio, la teoría del contrato independiente a primer requerimiento justifica esta cualidad de la boleta bancaria en el principio de la inoponibilidad de excepciones que emana del carácter autónomo y principal de la boleta. El banco garante no respondería de la obligación base contraída por el tomador-deudor, sino que habría asumido una obligación independiente frente al beneficiario.

De otra parte, esto supondría que el deudor no podría realizar alegaciones sustantivas o maniobras procesales tendientes a obstaculizar o impedir el pago de la boleta, pues esta se habría generado en una relación totalmente desvinculada del contrato base. Sin embargo, vemos que conforme a la regulación de la boleta bancaria, las partes pueden discutir la oportunidad del pago e impedir que este se practique. Ciertamente el acreedor podrá embargarla o precautoriarla para mejor aseguramiento de sus derechos, pero este aseguramiento no tendría sentido si no debe discutir primeramente la cuestión principal. Menos sentido tendría que el deudor pudiese solicitar una media precautoria, si no tiene como finalidad discutir el carácter del incumplimiento pretendido por el acreedor. Y esta es la razón que nos hace pensar que la teoría del contrato de garantía a primer requerimiento, con todos los méritos que presenta, no puede tener asidero en nuestro sistema.

autonomía y el sentido de su no accesoriedad. De manera similar, SAN JUAN CRUCELAEGUi (2004) p. 228, reconoce como elemento común de ambas figuras el de la inoponibilidad de excepciones, aunque reconoce la autonomía de la garantía a primer requerimiento.

$46 \mathrm{Y}$ esto es sin perjuicio que, como hemos visto, en la letra b) del numeral 1. 2 del Capítulo 8-11, la normativa parece entender que la boleta es un genuino efecto de comercio. 


\section{CONCLUSIONES}

Como hemos visto, las garantías constituyen un instituto complejo, en el que confluyen un número considerable de normas, tanto del Derecho civil, como del Derecho comercial y del procesal, pues en un sentido amplio comprenden todos los remedios y mecanismos de tutela del crédito o, más bien, del derecho personal que envuelve la situación jurídica crédito. Pero, en un sentido estricto, las garantías solo importan obligaciones propias o ajenas que están destinadas a asegurar directamente el cumplimiento de una obligación, o más exactamente, el deber jurídico de prestación del deudor. Generalmente, las garantías en sentido estricto se identifican con las cauciones, pero existen otras. Ello ocurre precisamente con la boleta bancaria de garantía, original de nuestro sistema y de gran aplicación práctica. Sin embargo, aún quedan pendientes problemas relacionados con la misma, que inciden en importantes aspectos prácticos. Por eso, nos hemos referido especialmente al concepto y a la naturaleza jurídica del instituto.

En este contexto, la normativa que la regula es bastante confusa y no permite arribar a una postura clara. Tanto el artículo $69 \mathrm{~N}^{\circ} 13$ de la Ley General de Bancos, como el Capítulo 8-11 de la Recopilación de Normas de la Superintendencia de Bancos e Instituciones Financieras permiten sostener que se trataría bien de una prenda de dinero o de un título valor, tal como hemos analizado. Sin embargo, ha de reconocerse que la circunstancia que la boleta pueda ser embargada por las partes, especialmente por el tomador, le priva a esta de su carácter abstracto. Sin bien es cierto que el banco garante no puede oponer excepción alguna para proceder al pago de la boleta, sino solo a petición del beneficiario acreedor, el tomador o deudor puede paralizar el pago de la misma discutiendo la cuestión de base, único marco procesal en el que podrá solicitar una medida precautoria sobre la boleta y, en este sentido, resulta evidente que el instrumento en análisis pierde el carácter autónomo que algunos autores le asignan.

\section{BIBLIOGRAFÍA CITADA}

BlANCO GÓMEZ, Juan José (1996): La cláusula penal en las obligaciones civiles: relación entre la prestación penal, la prestación principal y el resarcimiento del daño (Editorial Dykinson, 1 ${ }^{\text {a }}$ Edición, Madrid) $148 \mathrm{pp}$.

CAPRILE BIERMANN, Bruno (2002): La boleta bancaria de garantía. Una garantía a primer requerimiento (Editorial Jurídica de Chile, $1^{\text {a }}$ Edición, Santiago) 224 pp.

CARrasco PERERA, Ángel (1996): "Las nuevas garantías personales: las cartas de patrocinio y garantías a primer requerimiento” en: NiETO CARROL, Ubaldo, BONET SÁNCHEZ, José Ignacio (Coord), Tratado de garantías en la contratación mercantil. Tomo I. Parte General y garantías personales (Civitas, 1ª Edición, Madrid) pp 623 a 761.

De AmunÁtegui, Cristina (1993): La función de la cláusula penal en la jurisprudencia del Tribunal Supremo (Editorial Bosch, 1a Edición, Barcelona) 195 pp.

DíEZ-PICAZO, Luis (1983): Fundamentos de Derecho Civil patrimonial (Editorial Tecnos, $1^{\text {a }}$ Edición, Madrid) 890 pp. 
DíEZ-PiCAZO, Luis (1964): "El contenido de la relación obligatoria”, en: Anuario de Derecho Civil. Vol 17, N²: pp 349 a 366.

FUeYO LANERI, Fernando (1992): Cumplimiento e incumplimiento de las obligaciones (Editorial Jurídica de Chile, 2a Edición, Santiago) 652 pp.

GONZÁlEZ SAAVEDRA, Miguel (1962): La boleta bancaria de garantía (Editorial Jurídica de Chile, 1ª Edición, Santiago) 147 pp.

LECAROS SÁNCHEZ, José Miguel (1995): El contrato de prenda civil (Sociedad Editora Metropolitana, Santiago, 1a Edición) 253 pp.

López Santa María, Jorge (2005): Los Contratos, Parte General (Editorial Jurídica de Chile, $4^{a}$ Edición, Santiago) 624 pp.

PuElma ACCORSI, Alvaro (1971): Estudio jurídico sobre operaciones bancarias de Chile (Editorial Jurídica de Chile, $1^{\text {a }}$ Edición, Santiago) 349 pp.

Puelma ACCORSI, Alvaro (2006): Letra de cambio y pagaré, Ley $N^{\circ}$ 18. 092. Exposición, texto, fuentes y circunstancias (Editorial Jurídica de Chile, 2a Edición reimpresa, Santiago) $140 \mathrm{pp}$.

ROCA TRÍAS, Encarna (1996): "Rasgos básicos de la regulación española en materia de negocios de garantía”, en: NieTO CARrol, Ubaldo, Bonet SÁNCHEZ, José Ignacio (Coord), Tratado de garantías en la contratación mercantil. Tomo I. Parte General y garantías personales (Civitas, $1^{\text {a }}$ Edición, Madrid) pp. 127-163.

SÁNCHEZ-CALERO GUILARTE, Juan (1995): El contrato autónomo de garantía. Las garantías a primera demanda (Centro de documentación bancaria y bursátil, 1a Edición, Madrid) 429 pp.

SÁNCHEZ LERMA, Gemma (2001): “Contratos mercantiles de garantía”, en: DE LA Cuesta Rute, José María (Director), Valpuesta Gastamina, Eduardo (Editor), Contratos Mercantiles. (Editorial Bosch, Barcelona) Tomo II, pp. 227 a 328.

SANDOVAl LópeZ, Ricardo (2003): Contratos Mercantiles (Editorial Jurídica de Chile, $1^{a}$ Edición, Santiago) 744 pp.

SAN JUAN CRUCElAegui, Javier (2004): Garantías a primera demanda: contratación internacional e interna (Thompson-Civitas, Madrid) 623 pp.

Somarriva Undurraga, Manuel (sin año): Tratado de las Cauciones (Editorial ConoSur, 2a Edición, Santiago) 611 pp.

VAREla VAREla, Raúl (1948): "Comentario a la sentencia recaida en el juicio "Wessel Duval y Cía con Selzer y Schwarzenberg”, Revista de Derecho y Jurisprudencia Vol, 2a parte, Sección $1^{\mathrm{a}}$.

ViCent Chuliá, Francisco (1996): "Introducción al estudio de las garantías personales en el Ordenamiento español", en: Nieto CArrol, Ubaldo, Bonet SÁnChez, José Ignacio (Coord), Tratado de garantías en la contratación mercantil. Tomo I. Parte General y garantías personales (Civitas, 1 ${ }^{a}$ Edición, Madrid) pp 315 a 467.

WinTER IGUALT, Rodrigo (1995): Boleta de garantía (Instituto de estudios bancarios, $1^{\mathrm{a}}$ Edición, Santiago) 180 pp. 


\section{NORMAS CITADAS}

Ley $\mathrm{N}^{\circ}$ 19.382, Modifica Ley General de Urbanismo y Construcciones. Diario Oficial, 3 de febrero de 2004.

Ley $\mathrm{N}^{\circ}$ 20.007, Modifica Ley General de Urbanismo y Construcciones. Diario Oficial, 11 de abril de 2005.

Ley $\mathrm{N}^{\circ} 18.092$, Dicta nuevas normas sobre letra de cambio y pagaré y deroga disposiciones del Código de Comercio. Diario Oficial, 14 de enero de 1982

Ley $\mathrm{N}^{\circ}$ 18.852, Relativo al tratamiento de los títulos de crédito. Diario Oficial, 20 de septiembre de 1986.

Decreto con Fuerza de Ley $\mathrm{N}^{\circ}$ 3, Fija texto refundido, sistematizado y concordado de la Ley General de Bancos y de otros cuerpos legales que se indican. Diario Oficial, 19 de diciembre de 1997.

Decreto con Fuerza de Ley $\mathrm{N}^{\circ}$ 458, Ley General de Urbanismo y Construcciones. Diario Oficial, 13 de abril de 1976.

Capítulo 8-11, Boleta Bancaria de Garantía. Recopilación de Normas de la Superintendencia de Bancos e Instituciones Financieras.

\section{JURISPRUDENCIA CITADA}

Servicio de Vivienda y Urbanización Bío Bío Empresa de Servicios Sanitarios Bío Bío S. A. (2000): Corte de Apelaciones de Concepción, de 19 de julio de 2000 (recurso de apelación contra medida precautoria), disponible en bases de datos LexisNexis, número de indicador 22146, http://productos.lexisnexis.cl/NXT/lexisnexis. dll?f=templates $\& \mathrm{fn}=$ default.htm \&3.0\&Tit=A_Juridica/CL_JOL01\&vid=LNChile:65 (fecha de consulta: 30 de julio de 2007);

Dinamex Chile S. A. con Cuerpo Militar del Trabajo (1997): Corte de Apelaciones de Santiago, 27 de septiembre de 1996 (recurso de protección), Revista de Derecho y Jurisprudencia, tomo 94. II parte, sección quinta, pp 146-151;

Muñoz Guzmán, Manuel con Gobierno Regional de la VI Región Corte de Apelaciones de Rancagua (2007): 9 de febrero de 2007 (recurso de protección), disponible en bases de datos LexisNexis, número de indicador 35910, http://productos.lexisnexis.cl /NXT/lexisnexis.dll? f=templates $\& \mathrm{fn}=$ default.htm \&3.0\&Tit=A_Juridica/ CL_JOL01\&vid=LNChile:65 (fecha de consulta: 30 de julio de 2007);

Opazo Ramírez, Juan con Ilustre Municipalidad de Antofagasta (2005): Corte Suprema, 25 de mayo de 2005 (recurso de protección), disponible en bases de datos LexisNexis, indicador LexisNexis 32239, http://productos.lexisnexis.cl/NXT/ lexisnexis.dll? f = templates \&f $\mathrm{n}=\mathrm{default} . \mathrm{ht} \mathrm{m} \& 3.0 \& \mathrm{Tit}=\mathrm{A}_{-} J$ uridica/ CL_JOL01\&vid=LNChile:65 (fecha de consulta: 30 de julio de 2007) 